\title{
Kentiçi Toplu Taşıma Araçları için Performansa Dayalı Hakediş Sistemi: İstanbul Örneği Modeli
}

\author{
Uğur Cora ${ }^{1 *}$, Recep Kişla ${ }^{2}$, Özüm Asya $\mathrm{Su}^{3}$ \\ ${ }^{1^{*}}$ IETT İşletmeleri Genel Müdürlüğü, İstanbul, Türkiye, (ORCID: 0000-0002-7316-065X), ugur.cora@iett.gov.tr \\ 2 IETT İşletmeleri Genel Müdürlüğü, İstanbul, Türkiye, (ORCID: 0000-0002-7333-4090), recep.k1sla@iett.gov.tr \\ 3 IETT İşletmeleri Genel Müdürlüğü, İstanbul, Türkiye, (ORCID: 0000-0003-4765-9278), oakaynarca@iett.gov.tr
}

(İlk Geliş Tarihi 9 Mart 2021 ve Kabul Tarihi 21 Ekim 2021)

(DOI: $10.31590 /$ ejosat.893582)

\begin{abstract}
ATIF/REFERENCE: Cora, U., Kışla, R. \& Su, Ö A. (2021). Kentiçi Toplu Taşıma Araçları için Performansa Dayalı Hakediş Sistemi: İstanbul Örneği Modeli.Avrupa Bilim ve Teknoloji Dergisi, (31), 232-241.

Öz

Dünya genelinde toplu ulaşım hizmeti kamu ve özel sektör aracılığıyla, farklı sözleşme modelleri çerçevesinde yürütülmektedir. Bu kapsamda en çok tercih edilen sözleşme modeli Kalite Teşvikli Brüt Maliyet Sözleşme Modelidir. Bu sözleşme modelinde sağlanan hizmetin kalitesi ve gelirin gideri karşılama oranının arttırılması ile verilen sübvansiyon miktarlarının azaltılması esas alınmaktadır. Türkiye'de ise toplu ulaşım hizmetinin önemli bir kısmı özel sektör aracıllı̆̆ıyla, Net Kontrat Maliyet Sözleşmeleri ile gerçekleştirilmektedir. Uygulanan sözleşme modelinde kamu ve toplu ulaşım işletmecileri için karşılıklı kazanç ilişsisi göz önünde bulundurulmaktadır. Özellikle lastik tekerlekli ulaşım sistemleri için gelirin gideri karşılama oranının yüksek ve planlamanın stabil olduğu koşullarda tercih edilen bu model; günümüzde artan maliyetler ve gelişen raylı sistem ağı ile beraber yeni hat planlamalarını ile mevcut hatların reorganizasyonunu gerekli kılmakta dolayısı ile mevcut model ile devam edilmesini bir hayli zorlaştırmaktadır. .

İstanbul Büyükşehir Belediyesi, İETT İşletmeleri Genel Müdürlügü tarafından 2016 yılında tamamlanan TUYS Projesi (Toplu Taşıma Yönetim Sistemi) kapsamında ortaya konulan yeni sözleşme modeli esasınca, mevcut durumdaki sorunlara çözüm sunularak; işletmecilerin gelir riskinden bağımsız, kısmi performans kriterlerini esas alan yenilikçi bir yaklaşım ortaya konulmuştur. Yeni model ile toplu ulaşımın bütün modlarında entegrasyona ve esnek planlamaya imkân sağlayan, işletmecilerin gelir kaygısını ortadan kaldıran, ayrıca sunulan hizmetin kalitesini beraberinde müşteri memnuniyetini arttıracak sürdürülebilir bir sözleşme konsepti tasarlanmıştır. Bu çalışmada İstanbul için, toplu taşıma hizmeti sunan ilgili otorite ve operatörler arasındaki ilişkilerin düzenlendiği yeni sözleşme modeli incelenmiştir. İstanbul'da özel halk otobüsü işletmecisi statüsünde hizmet veren 3.041 özel taşımacının COVID-19 öncesi son 6 aylık işletme ve finansal verileri analiz edilerek, yeni modelle çalışması durumunda 2 modelin finansal açıdan çok yönlü değerlendirmesine yer verilmiştir.
\end{abstract}

Anahtar Sözcükler: Kent İçi Toplu Ulaşım, Performansa Dayalı Hakediş Modeli, Toplu Ulaşım Finansmanı, İstanbul Toplu Ulaşım Sistemi

\section{Performance-Based Regulation for Public Transport Systems: A Case Study Model in İstanbul}

\begin{abstract}
Public transportation opearation runs different contract models by public and private sectors all around the world. The most pereferable contracting model is performace based contracting model in this perspective. This contracting model basis that increase provided servise quality and return of investment rate unlike decrease subsidy amount. Most of public transportation opeartions runs by private sector based on net contracting model. Applied that model which is operated by public and private cooperation depend on win win model.

Net contracting model is preferred beneath stabil planning facility and high return of investment rate, but nowadays has to reorganized under increasing cost and developing rail system roand with new route planning. In this situation makes effectiveness of current model debatatable. Based upon new contracting model put forward within the scope of TUYS(Public Transportation Management System Preject) completed by İBB, IETT General Directorate in 2016, by offerin solutions to the existing problems; an innovative approach based ob partial performance criteria independent of the income risk of the income risk of the operator has been presented. With this model which is put forward by İETT, give chance to integrated and flexible planning, get rid of income concern, surge service quality and customer satisfaction for all transportation models. In this article is examined new model for model for authority and operator which responsible for operate public transportation new model for İstanbul. İn the current situation, payment based on new contracting model
\end{abstract}


for average scale line is examineted and compareted with the old model and the financial multi-dimensional evaluation of new model in terms of operator and authority is included.

Keywords: Urban Public Transportation, Performans Based Public Transportation System, Public Transportation Finance, Istanbul Public Transportation System

\section{Giriș}

Dünyada her geçen gün artan nüfus birçok konuda yenilikçi yaklaşımları zorunlu kılmaktadır. Bunların başında toplu ulaşım hizmetleri gelmektedir. Şehirlerdeki toplu ulaşım hizmetlerinin çekici hale getirilebilmesi, mevcut durumdaki olumsuz etkileri azaltarak veya en azından bu etkilerin kontrol altına alarak mümkün kılınabilmektedir. Aynı zamanda şehirlerin gelişmişliği ile de doğru orantılı olan toplu ulaşım sistemleri, hareketliliği arttırarak sosyal ve ekonomik açıdan da fayda sağlamaktadır.

Sürdürülebilir şehir konsepti endeksine göre ise şehirlerdeki toplu ulaşım hizmeti 3 ana kategori üzerinden değerlendirilmektedir. İlk kriter olan insan faktörü, şehir içindeki seyahat kalitesine, ikinci kriter seyahat araçlarının ne kadar çevreci olduğuna, son kriter ise ulaşım sistemlerinin karlılığına dair analizler gerçekleştirerek yaklaşım sunmaktadır. Bu son değerlendirme kriterine göre finansal açıdan karlı toplu ulaşım sistemleri, sürdürülebilir toplu ulaşım açısından önem teşkil etmektedir.

İstanbul'da toplu ulaşım hizmetleri kamu ve özel sektör kaynaklarıyla sunulmaktadır. Karayolu ve denizyolu ulaşımında hem kamu hem özel sektör kaynaklarıyla birlikte hizmet veriliyorken, raylı sistemlerde yalnızca kamu kaynaklarıyla hizmet sağlanmaktadır. Mevcut durumda özel sektör aracılığıyla verilen toplu ulaşım hizmetleri, kurumsal bir yapıdan uzak, bireysel işletmeciler tarafından yürütülmektedir.

İstanbul Büyükşehir Belediyesi (İBB), tam entegre, esnek, güvenli, verimli ve konforlu bir toplu taşıma hizmeti sağlayabilmek için, kendisine bağlı olan özel işletmecilere sundukları hizmetlere karşılık yapılan hakediş ödemelerinde Net Maliyet Sözleşme Modelinden performansa dayalı hakediş sistemini esas alan Brüt Maliyet Sözleşme modeline geçiş yapmıştır. Konuyla ligili olarak hazırlanan "İstanbul Toplu Taşıma Yönetmeliğii” de İBB Meclisince kabul edilmiştir (İBB, 2020).

Yürütülen uzun soluklu çalışmalar ve TUYS projesi sonucunda, İstanbul toplu ulaşım sisteminin de yapısı göz önünde bulundurularak; lastik tekerlekli toplu ulaşım sistemleri için performansa dayalı hakediş ödemesini esas alan Kalite Teşvikli Brüt Maliyet Sözleşme Modeline geçişin gerekliliği ortaya konulmuştur. Bu kapsamda bugüne kadar kullanılan Net Maliyet Sözleşme Modeline dair aşağıdaki hususlar tespit edilmiştir;

- Hizmet sunulan hatlarda rekabeti teşvik etmekte; bu durum daha fazla yolcu taşıma isteğini artırdığı için hizmet kalitesini düşürmektedir.

- Özel sektör tarafindan karlılığın yüksek olduğu hatlarda çalışmaya yönelik taleplere neden olmakta; bu durum planlamaya dair kisitlar ve etkin planlama sağlanamamasına neden olmaktadır.

- Farklı hatlar arasında gelirin gideri karşılama oranlarında meydana gelen farklılıklar, işletmecilerin gelir dağılımında dengesizliklere neden olmakta; bunun sonucu olarak sanal hat değerleri oluşmaktadır.
- Operatörlerin performanslarını arttırmaya yönelik teşvik mekanizması bulunmamaktadır.

Sürdürülebilir toplu ulaşım sistemi için sahip olunan kaynakların etkin ve verimli olarak planlanabileceği, birbirleriyle entegrasyonun sağlanabileceği yenilikçi bir hakediş modelinin kurgulanması bu anlamda çok önemlidir.

\section{Literatür Araştırması}

Dünya örneklerine bakıldığında toplu ulaşım sistemlerinde birçok otorite ve operatörün benzer yaklaşımlar sergiledikleri görülmüştür.

Bu kapsamda ilk olarak güçlü entegrasyon sağlanması için ortaya konulan uygulmalar göze çarpmaktadır. Dünyanın önde gelen şehirlerinde otoriteler tarafindan toplu ulaşımda planlama ve koordinasyonun sağlanılmasının yanısıra beraberinde ücretlendirme, bilgilendirme ve düzenlemeler ile ilgili daha büyük ölçekli ve bütüncül yaklaşımlar sergilenmektedir.

Ayrıca toplu ulaşım sistemlerinde kamu imkânları sunulmasına alternatif olarak farklı otoriteler tarafindan pazar içerisinde rekabet potansiyeli oluşturulmaktadır. Buna bağlı olarak İETT gibi otoriteler operatör gibi hizmet sunmak yerine, hizmet yükümlülüklerini uygulatmaktan sorumlu merciler olarak rol almaktadırlar.

$\mathrm{Bu}$ ve benzeri eğilimler, ortaya konulan toplu ulaşım piyasa rekabeti ile uyumlu hibrit yapıların benimsenmesini sağlamaktadır. Otoriteler, proaktif planlama ve çok yönlü güçlü entegrasyon sağlayarak hibrit hizmet sözleşmeleri ile yenilikçi hakediş sistemlerini uygulanabilir kılarak, sürdürülebilir toplu ulaşım hizmeti sunmayı amaçlamaktadırlar.

Bu kapsamda dünya şehirlerinin eğilimleri aşağıdaki Şekil1'de gösterilmiştir.

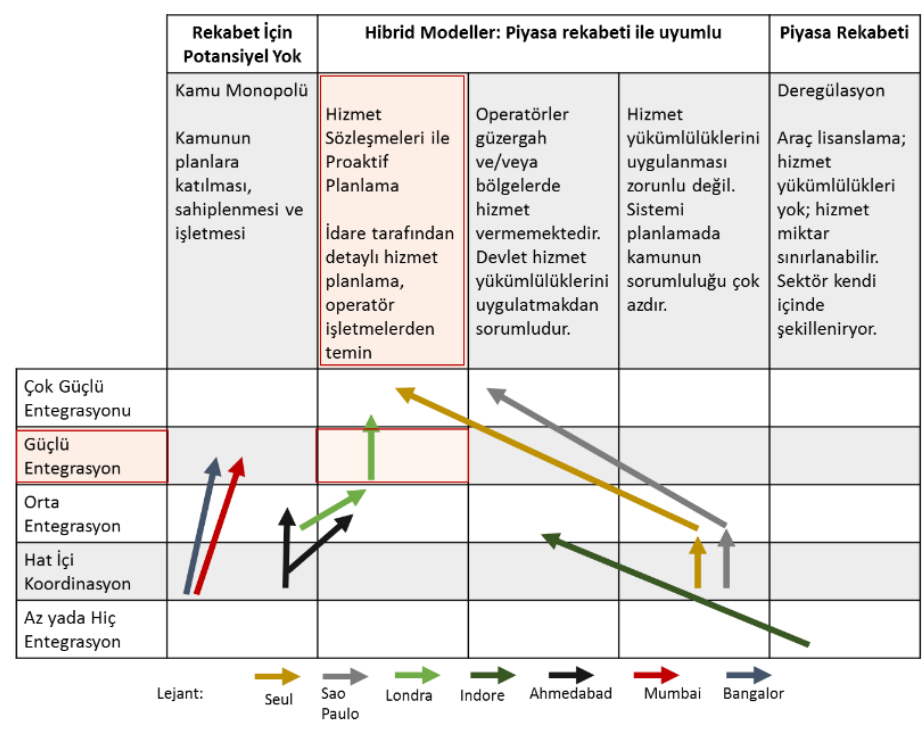

Şekil 1. Şehirlerin Sözleşme Tipi Tercihi (UITP, 2016c) 


\subsection{Toplu Ulaşım Sözleşme Çeşitleri}

Toplu ulaşım sistemlerinde dünya genelindeki uygulamalar ve akademik çalışmaların incelenmesi sonrasında operatörler ile otoriteler arasında sunulan hizmete ilişkin farklı yaklaşımları esas alan sözleşme türlerinin yer aldığı tespit edilmiştir. Genel manada söz konusu sözleşmeler operatör ve otoritenin arasında ortaya çıkan risklerin paylaşımına göre şekillenmektedir. (Saussier,2015)

Bu kapsamda ortaya çıkan riskler;

- Maliyet Riski

- Gelir Riski

- Pazar Riski

- Performans Riski

- Verimlilik Riski

- Altyap1 Riski

- Yatırım Riski

- Rekabet Riski

- Mevzuat Riski

- İtibar Riski

Yukarıda yer verilen riskler arasından toplu ulaşımda kullanılan sözleşmelere esas en önemli riskler maliyet ve gelir riskleridir. Diğer riskler yan unsur olarak değerlendirilmektedir. Araç alım, bakım, işçilik, yakıt (enerji) maliyetleri ile genel giderler gibi ana girdilerin beklenenin üzerinde değişime uğraması maliyet risklerini oluştururken; yolculuk ücretleri ve yolculuk talebindeki beklenenin altında değişim gerçekleşmesi ise gelir risklerine sebep olmaktadır.

Dünya geneline bakıldığında zamana bağlı yolculuk gelirinin giderleri karşılama oranı Avrupa'da \%50, Amerika'da \%35, Asya'da \%85 civarında olduğu görülmektedir. Bu iki temel risk kaleminin otorite ve operatör arasında paylaşılması durumuna göre toplu ulaşım sistemlerinde sözleşme modelleri şekillenmektedir (UITP, 2016).

Dünya genelinde toplu ulaşım sistemlerinde yürütülen sözleşmelere esas kullanılan 4 ana model yer almaktadır;

Net Maliyet Sözleşme Modeli: Operatör maliyet ve gelir riskini üstlenmektedir. Otorite operatörlere doğrudan veya ihale yöntemiyle işletme hakkını verir. İşletme gelirleri çoğunlukla yolculuk gelirinden oluşur. İstanbul toplu ulaşımında Halk otobüsleri, minibüsler ve Metro İstanbul A.Ş. bu sözleşme modeli ile işletilmektedir (Camen, 2011). Net Maliyet Sözleşmesi dünyada en az uygulanan sözleşme olmasına karşın Türkiye'de en çok kullanılan sözleşme modelidir.

Brüt Maliyet Sözleşme Modeli: Maliyet riskini operatör üstlenirken gelir riskini otorite üstlenmektedir. Operatöre verdiği hizmet karşılığında kilometre başı ve/veya çalışma süresi esas alınrak ödeme gerçekleştirilmektedir. Otoritenin topladığı ücret hizmet bedelinden fazla ise otorite kar etmiş olurken, gelir gideri karşılayamaz ise otorite sistemi sübvanse eder. Rekabete açık pazarlarda en yaygın kullanılan sözleşme türü olarak Brüt Maliyet Sözleşmeleri karşımıza çıkmaktadır. Net Maliyet Sözleşmelerinde yolda rekabet gerçekleşirken, Brüt Maliyet Sözleşmelerinde yol için rekabet edilir (UITP, 2010).

Uygulamada en fazla karşımaza çıkan Net ve Brüt Maliyet Sözleşme Modelleri arasındaki temel farklılık, maliyet ve gelir risk paylaşımıdır. Net Maliyet Sözleşmesi gelirlerin belirsizliği nedeniyle istikrarsız durumları oluşturmaktadır. Brüt Maliyet Sözleşmesinde Net Maliyet Sözleşmesinden farklı olarak operatöre sadece kat edilen mesafe üzerinden ödeme yapıldığ 1 için yolcu memnuniyetinde düşüş olasıdır. Sözleşme türlerinde trendin Kalite Teşvikli Brüt Maliyet Sözleşmesine doğru yön değiştirdiği görülmektedir.

Kalite Teşvikli Brüt Maliyet Sözleşme Modeli: Otorite, operatörden önceden planlanan hizmet kriterlerine göre hizmet alımı yapmaktadır. Aynı şekilde operatör maliyet riskini üstlenirken, otorite de gelir riskini üstlenmektedir (UITP, 2016b). Brüt Maliyet Modelinde işletmeciye genellikle km ve zaman üzerinden ödeme yapıldığı için hizmet kalitesini ve yolcu memnuniyetini artırmaya yönelik herhangi bir teşvik bulunmamaktadır. Kalite Teşvikli Brüt Maliyet Sözleşmesi, Brüt Maliyet Sözleşmesine ek olarak belirlenen performans kriterlerine göre ödül/ ceza sistemi ile bu sorunların giderilmesini esas alır. Belirlenen performans kriterleri çeşitli denetim faaliyetleri (memnuniyet araştırmaları, gizli müşteri araştırmaları ve yazılım göstergeleri) ile denetlenmektedir. (Walters,2008) $\mathrm{Bu}$ denetim faaliyetleri ile toplu ulaşımda verilen hizmet kalitesi ölçülmekte ve yönetilmektedir (UITP, 2016).

Yönetim Sözleşme Modeli: Hem maliyet hem de gelir riskini otorite üstlenir. Otorite profesyonel bir yönetim hizmeti satın almaktadır. Yani operatör sadece operasyonun yönetimini yapmaktadır (UITP, 2016c). Yönetim Sözleşme modelinin en bilinen uygulaması Dubai'de işletilmektedir. Dubai'de İngiliz firması olan Serko şirketi bu model ile raylı sistemlerin operasyonlarını yürütmektedir (Yıldızgöz, 2010).

Yukarıda incelenen sözleşme modelleri maliyet ve gelir risklerine göre karşılaştırılması Tablo-1 de verilmektedir.

Tablo 1. Sözleşme Modelleri Maliyet ve Gelir Risk Karşılaştırması

\begin{tabular}{|l|c|c|}
\hline Model Tipi & $\begin{array}{c}\text { Maliyet } \\
\text { Riski }\end{array}$ & $\begin{array}{c}\text { Gelir } \\
\text { Riski }\end{array}$ \\
\hline Net Maliyet Sözleşme Modeli & Operatör & Operatör \\
\hline Brüt Maliyet Sözleşme Modeli & Operatör & Otorite \\
\hline $\begin{array}{l}\text { Kalite Teşvikli Brüt Maliyet } \\
\text { Sözleşme Modeli }\end{array}$ & Operatör & Otorite \\
\hline Yönetim Sözleşme Modeli & Otorite & Otorite \\
\hline
\end{tabular}

\subsection{Londra - TfL}

Londra'daki toplu taşıma sistemlerinden sorumlu olan Transport for London (TfL) entegre bir kurum olarak 2000 yılında kurulmuştur. TfL'in birincil rolü, Londra Belediyesinin ulaşım stratejilerini uygulamak ve başkent genelinde taşıma hizmetlerini yönetmektir. TfL yapı itibariyle; hem Ulaştırma Bakanlığı yoluyla merkezi hükümete hem de Belediyeye bağlıdır ve kendine bağlı şirketler grubundan oluşmaktadır. TFL, ulaşım otoritesi olarak yalnızca toplu ulaşım ile değil sinyalizasyon, trafik yönetimi, trafik sıkışıklık ücretlendirmesi (congestion charging) gibi konularla ulaşımın tamamı ile ilgilenmektedir (Amaral, 2012).

TfL'in Londra genelinde sorunmlu olduğu toplu ulaşım hizmet kolları aşağıda gösterilmektedir.

- Londra Otobüsleri

- Londra Metroları

- DLR (Hafif Metro)

- Nehir Servisleri

- Victoria Coach İstasyonu (Otobüs Terminali) 


\section{- Overground (Tramvay)}

TfL'in toplu ulaşım otoriteliliği kapsamında sorumlu olduğu alanlar aşağıda gösterilmiştir.

- Paralı yolları yönetmek

- Londra trafik hizmetlerini yürütmek (trafik sinyalizasyonu, trafik polisliği vb)

- Ticari araç kiralamaları ve taksilerin yönetmek

- Yürüme ve bisiklet yollarını yapmak

- Engelli insanlar için toplu ulaşımı erişebilir hale getirmek

TfL'in lastik tekerlekli toplu ulaşım hizmetleri(otobüsler) için gerçekleştirdiği otorite-operatör sözleşmeleri esas alınarak söz konusu İstanbul toplu ulaşım sistemi için öngörülen yeni hakediş modeline örnek teşkil edecek hususlara aşağıda yer verilmiştir. TfL tarafinda yapılan sözleşmeye göre;

- Arriva, First Group, Go Ahead gibi 7 operatör ile otorite arasında gerçekleşmiştir.

- Her operatör ile ayrı anlaşma imzalanmaktadır.

- Sözleşmeye göre işletmeciler rekabet koşulları içerisinde ihale ile belirlenir.

- Sözleşme Kalite Teşvikli Brüt Maliyet Sözleşmesidir.

$\checkmark$ Maliyet riski operatöre aittir.

$\checkmark$ Gelir riski otoriteye aittir.

- Sözleşmelerin süresi 5+2 yıl olarak (Raylı sistemlerde $7+2$ yıldır) belirlenmiştir.

- Sözleşme kapsamında gerçekleştirilen hakediş; işletmecilerin gerçekleştirdiği yol uzunluğu $(\mathrm{mil} / \mathrm{km})$ ve hizmetin genel güvenilirliğine (zamanındalık) göre yapilır.

- Sistemdeki otobüsler operatöre ait olabildiği gibi operatör tarafından kiralanmış da olabilmektedir.

\section{Sözleşme Ödemeleri ve Gelir}

Operatörler, aylık periyotlarda belirlenen hesap dönemleri için toplamda 13 dönem, her yılın nisan ayından bir sonraki yılın mart ayına kadar çalışır.

Ödemelerin 75\%'i ilgili dönem içerisinde, kalan kısmı ise varsa yapılacak kesintilerden (kayıp kilometre vb.) sonra süreç sonunda yapilır (Cantillon, 2006).

TFL'in uyguladığı Kalite Teşvikli Sözleşme ile 3 farklı bonus/ceza ödemeleri gerçekleşmektedir;

- Güvenilirlik Performans Ödemeleri

- Sözleşme Uzatma

- Kalite Performans Ödemeleri

\subsection{Singapur - LTA}

Land Transport Authority (LTA), Singapur Ulaşım Bakanlığı bünyesinde 1995 tarihinde şehir içi hareketliliği sağlamak üzerine her alanında yasal olarak yetkilendirilmiş bir kurumdur. Tüm toplu ulaşım modlarını düzenleme, denetleme ve koordinasyon yetkisi otoriteye verilmiştir.

LTA' nın yanı sıra Singapur toplu taşımasında önemli rol oynayan bir diğer aktör de kanun ile kurulmuş olan Toplu Taşıma Konseyi (Public Transportation Cuncil, PTC)'dir. PTC otobüs ve tren araçlarının bilet ödeme hizmetlerini ve ücret tarifelerini düzenleyen, buna ek olarak da Ulaşım Bakanlığı'nı toplu ulaşım konularında besleyen bağımsız bir yapıdır. (Leong,2016)
LTA, merkezi otobüs ağı planlayıcısı olarak sistem maliyetlerini dengelerken yolculuk kalitesini arttırmaya odaklanan etkili, entegre ve sürdürebilir bir lastik tekerlekli toplu ulaşım sistemini sağlamayı hedeflemektedir. LTA, hedefleri doğrultusunda Otobüs hatları işletimi için Brüt Maliyet Sözleşme Modeli uygulamaktadır.

LTA tarafindan gerçekleştirilen sözleşmeye göre;

- Tower Transit, Go-Ahead, SBS Transit ve SMRT Buses gibi operatör ile otorite arasında gerçekleşmiştir.

- Her operatör ile ayrı anlaşma imzalanmaktadır.

- Sözleşmeye göre işletmeciler rekabet koşulları içerisinde ihale ile belirlenir.

- Sözleşme Brüt Maliyet Sözleşmesidir.

$\checkmark$ Maliyet riski operatör üstlenir.

$\checkmark$ Gelir riski otorite üstlenir.

- Sözleşme süresi 5+2 yıl olarak belirlenmiştir.

- Sözleşmeler 1 Eylül 2016 yılında uygulamaya alınmıştır.

- Bilet gelirlerini otorite toplar.

- Hakediş ücretleri performans standartlarına göre hizmet vermek üzere yapılan kilometreye göre dağıtılır. (Hizmet Kalite Standartlarına göre mali cezalar uygulanir.)

- Otorite tüm otobüs varlıklarına sahip olup işlettirilmesini Brüt Maliyet Sözleşmesine göre sağlamaktadır.

PTC, araçlarını korumak ve otobüs hizmetini sağlamak için tüm operatörlerin bağlı kaldığı hizmet kalitesi standartlarını oluşturmuştur. $\mathrm{Bu}$ standartların uygunluğu oluşturulan kurullar vasitasılla denetlenmekte ve uygulanabilirliği sağlanmaktadır (Leong, 2016).

\section{3. İstanbul Toplu Ulaşımı Mevcut Durum Analizi ve Yenilikçi Yaklaşım}

İstanbul toplu ulaşım sistemi kamu otoritesi tarafından regüle edilmekte; bu kapsamda kamunun da içerisinde yer aldığı bireysel ve kurumsal operatörler tarafindan farklı sözleşme modelleri ile işletilmektedir. Lastik tekerlekli toplu ulaşımın önemli bir oranı bir kamu kurumu olan İETT İşletmeleri Genel Müdürlüğü tarafından yürütülürken, bir kısmı süreli diğer bir kısmı da süresiz (tahditli) çalışma lisanslarına sahip olan bireysel taşımacılar tarafindan Net Maliyet Kontrat Modeli ile işletilmektedir.

Net Maliyet Kontrat Modeli ile ifa edilen toplu taşıma hizmetinde hizmetin üretimi için katlanılan maliyetler sadece yolculuk gelirleri ile karşılanmış ancak, yapılan düzenlemeler ile toplu taşımada ücretsiz ve indirimli tarifeden yararlanan kesimlerin sayısı arttıkça zaman içinde yolculuk gelirlerinin cari işletme giderlerine yetmediği; akaryakıt, işçilik, amortisman, sigorta, tazminat ödemeleri ve bakım giderlerindeki artışa karşılık yolculuk ücretlerindeki artışlar yetersiz kalmış, yolculuk gelirleri ile genel giderler karşılanamaz hale gelmiştir. Bu durum, toplu taşıma hizmetinin sürdürülebilirliğini ciddi şekilde tehdit etmiştir. Bununla beraber artan ulaşım ihtiyaçlarına istinaden yapılan raylı sistem ağının genişlemesi, daha çok yolcu kapasiteli araçlara toplu taşımanın özendirilmesi, lastik tekerlekli toplu taşıma araçlarının daha esnek ve planlanabilir bir modelle ana hattın omurgasını oluşturan raylı sistem ağlarına besleme hatları oluşturacak yeni bir model arayışına sevk etmiştir. 
Otobüslerle yapılmakta olan toplu taşıma hizmetinde elde edilen yolculuk gelirlerinin işletme giderlerini karşılamaması, taşıma kapasitesine rağmen araç ve sefer başına yolculukların uluslararası standartlarda olmaması (standart $\mathrm{m}^{2}$ başına 4 yolcu, yoğun hatlarda 8 yolcuya kadar çıkabilmekte), yolcu memnuniyeti sağlayacak esnek planlama yapılamaması gibi nedenlerle, kaynakların daha verimli bir şekilde kullanılması amacıyla toplu taşıma işletme modelinin idare eliyle yeniden yapılandırılması zorunlu hale gelmiştir. (İmre,2017)

Dünya ölçeğindeki toplu taşıma sisteminin devlet veya kamu otoritesi eliyle desteklenmeden sürdürülebilir bir yöntem olmadığı kabul edilmiştir. Bu kapsamda özel işletmecilere, öğrenci ve yaşlı vatandaşlarımız gibi diğer yolcu gruplarına uygulanan indirimli ve ücretsiz tarifelerin maliyetleri ile artan işletme maliyetlerini kısmen hafifletmek amaciyla destekleme ödemeleri yapılmaktadır. Net Maliyet Kontrat modelinde yapılan destekleme ödemeleri;

\section{- Yolculuk Basım Sübvansiyon Desteği \\ - Öğrenci Abonman Fark Desteği \\ - Ücretsiz Gün (Bayram, Sinav vs) Sübvansiyon Desteği \\ - Covid-19 Sübvansiyon Desteği \\ - Ücretsiz Yolcu (65+) Sübvansiyon Desteği (Aile ve Sosyal Politikalar Bakanlığı) şeklindedir.}

Net Kontrat Modeli ile işletilen mevcut toplu taşıma işletme modeli, işletmecilerin yolculuk gelirlerine dayalı olup özellikle özel işletmeciler bakımından toplu taşıma hizmetinin sürdürülebilirliği daha fazla yolcu taşıma imkânına bağlı olmaktadır. Bu durum; özel işletmecileri yolcu yoğun hatlarda çalışma ve tek seferde daha fazla yolcu taşımaya teşvik ettiğinden, yolcular bakımından standartların üzerinde yoğun araçlarda seyahat etme konforsuzluğu, toplu taşıma sisteminin tamamında ise mevcut kapasiteyi verimli bir şekilde kullanamama sonucunu doğurmaktadır. Ayrıca hatların gelir durumlarının farklı olması, mevcut sistemde dengesiz bir gelir dağılımına ve rekabete sebep olmaktadır. İşletmeciler arasındaki bu rekabet, kaynaklar planlanırken esnek planlama yapılamamasına, yeni açılan metro sistemleri ve şehirde oluşan yeni çekim merkezlerinin değiştirdiği yolculuk taleplerinin yeterince karşılanamamasına neden olmaktadır.

Yukarıda anlatılan sorunlara yönelik hususlara bağlı olarak, toplu taşıma hizmet kalitesinin düşmesi, değişen ulaşım ihtiyaçlarına karşın etkin planlama yapılamaması ve mevcut durumda işletmecilerin performanslarını artırmaya yönelik herhangi bir teşvikin bulunmaması, mevcut gelir sisteminin işletmeciler arasında adaletsizliğe sebep olması ve sürdürülebilir olmaması gibi sebeplerden dolayı taşımacıların kar kaygısını ortadan kaldıracak, yolculuk gelirinden etkilenmeyen yeni bir gelir paylaşımı sisteminin kurgulanma ihtiyacı doğmuştur.

Bireysel işletmecilerin kurumsallık kazanamamasından dolayı literatür kısmında yer verilen iyi uygulama örneklerinin İstanbul koşullarında bire bir uygulanması mümkün gözükmemektedir. Bu sebeple araç bazlı bir hakediş modeli oluşturulması öngörülmüştür.

Bu kapsamda sisteme dair birtakım kısıtlar belirlenmiştir.

- Toplu ulaşım hizmeti sunan her taşımacının, hizmeti karşılığı yapılan hakediş ödemesinin bağımsız hesaplanması
- Kullanılan araçların kapasite, uzunluk ve yaş değerlerine göre ödemeye esas maliyet kalemlerinin farklılaştırılması

- Bağımsız her taşımacının farklı hat ve km'lerde çalışmasına karşın maliyetlerini karşılayıp eşit kar elde etmesi

- Araçların çalıştığı güzergâha göre işletme hızının değişmesi dolayısı ile yakıt tüketiminin dinamik hesaplanmas1

- Her aracın belirli döngüde eşit km yapmasının sağlanması

\section{1. İstanbul için Önerilen Hakediş Modeli}

Mevcut raylı sistem altyapısı ve planlanan altyapı gözetilerek özel halk otobüslerinin çalışmış oldukları güzergahların optimum faydanın sağlanması amaciyla yeniden planlanması ve esnafın yolculuk kaybı endişesi yaşamaması, her bir güzergah değişikliğini yargısal denetime taşımaması ve adil kazanç sağlanabilmesi için sunmuş oldukları hizmet karşılığında "sabit maliyet + değişken maliyet + kar esaslı", kilometre bazlı hakediş sistemi tasarlanmıştır.

Sabit ödeme bir aracın bir ay boyunca hizmet sunmaması durumunda dahi ortya çıkan maliyetler (personel, amortisman, kasko, trafik sigortası vb.) olup, değişken maliyetler ise km başı yakıt ve bakım\& onarıma esas maliyet kalemlerinden meydana gelmektedir.

Hatların farklı çalışma koşulları; Trafik yoğunluğu, yol altyapıs1, yol eğimi, indi bindi süreleri vb.gibi nedenlerle söz konusu hatlarda çalışan araçların ortalama yakıt tüketim miktarları değişiklik göstermektedir. Yakıt tüketimine etki eden bu farklılı̆ 1 normalize etmek amaciyla hat efor katsayısı modellenmiştir.

Geliştirilen model ile özel taşımacıların beklentilerinin karşılanması, gelir ve gider kaygılarının ortadan kalkması ve adaletli bir gelir sistemi ile birlikte sürdürülebilir toplu ulaşım sistemi için tüm kısıtların ortadan kaldırılarak daha etkin planlama yapılabilmesi amaçlanmıştır.

Sürdürülebilir toplu ulaşım sistemi için ortaya konulan Yeni Modele esas hakediş hesaplaması;

$$
A=S G O \times(S O ̈+P O ̈)+(H E K \times Y M+B O M) \times G K+V
$$

Burada;

$$
\begin{aligned}
& \text { - } \mathrm{A}=\text { Araç Başı Hakediş Tutarı } \\
& \text { - SGO = Sefer Gerçekleştirme Oranı } \\
& \text { - } \mathrm{SÖ}=\text { Sabit Ödemeler } \\
& \text { - } \mathrm{PÖ}=\text { Performans Ödemesi } \\
& \text { - HEK = Hat Efor Katsayısı } \\
& \text { - YM = Yakıt Birim Ödeme } \\
& \text { - } \mathrm{BOM}=\text { Bakım \& Onarım Birim Ödeme } \\
& \text { - } \mathrm{GK}=\text { Gerçekleşen Km } \\
& \text { - } \mathrm{V} \quad=\text { Vergi }
\end{aligned}
$$

* Vergi: Tüm maliyetler toplamının (performans ödemesi hariç) \%3,75'i olarak hesaplanacaktır. 
Sefer Gerçekleştirme Oranı (SGO):

$$
\begin{gathered}
S G O=(P G S+E P G) /\left(P S+P E S-\sum O K\right) \\
\times(C ̧ G / T G)
\end{gathered}
$$

- $\mathrm{PGS}=$ Plan Gerçekleșen Sefer Sayısı

- $\quad \mathrm{EPG}=$ Ek Plan Gerçekleşen Sefer Sayısı

- $\mathrm{PS}=$ Planlanan Sefer Sayıs

- PES = Planlanan Ek Sefer Sayısı

- $\mathrm{OK}_{\mathrm{N}}=$ İETT (Trafik, Toplumsal Olay, idari görev vb.) Kaynaklı Zayi Sefer Sayısı

- $\quad \dot{I} K_{N}=$ İssleten Kaynaklı Zayi Sefer Sayısı

- $\quad$ ÇG = Uygulama Ayı Çalışılan Gün Sayısı

- $\quad \mathrm{TG}=$ Uygulama Ayı Toplam Gün Sayıs1

Uygulama Ayı Toplam Gün Sayısı: Uygulama ayında İETT tarafindan mücbir sebeple planlama yapılmayan günler varsa düşüldükten sonra kalan takvim günü sayısını ifade eder.

Zayi seferler İETT ve işleten kaynaklı olarak tasnif edilir. Sefer gerçekleştirme oranı hesaplanırken, İETT kaynaklı gerçekleşmeyen seferler zayi kabul edilmez. (EK-1)

Sabit Ödemeler: Km'den bağımsız olarak oluşan maliyet kalmeleri; Personel, Amortisman, Kasko, Motorlu Taşıtlar Vergisi (MTV) vb. EK-2.

Sabit maliyetler içindeki amortisman bedeli 10 yıllık ekonomik ömür üzerinden hesaplanmış olup, 10 yaşından büyük araçlar için bu bedel ödenmez.

Hat Efor Katsayısı (HEK): Hatların farklı çalışma koşulları; Trafik yoğunluğu, yol altyapısı, yol eğimi, indi bindi süreleri vb.gibi nedenlerle söz konusu hatlarda çalışan araçların ortalama yakıt tüketim miktarları değişiklik göstermektedir. Yakıt tüketimine etki eden bu farklılığı normalize etmek amacıyla hat efor katsayısı modellenmiştir.

Tablo-2'de Hat Efor Katsayısı (HEK) esas bazı parametrelere yer verilmiştir.

\section{Tablo 2. HEK Hesaplama Girdileri}

\begin{tabular}{|l|c|}
\hline Km Başına Maksimum Yakıt $(\mathrm{Lt} / \mathrm{Km})$ & 0,55 \\
\hline Km Başına Minimum Yakıt $(\mathrm{Lt} / \mathrm{Km})$ & 0,30 \\
\hline Km Başına Ortalama Yakıt $(\mathrm{Lt} / \mathrm{Km})$ & 0,45 \\
\hline Maksimum $\mathrm{Hız}(\mathrm{Km} / \mathrm{Sa})$ & 39,4 \\
\hline Minimum $\mathrm{Hız}(\mathrm{Km} / \mathrm{Sa})$ & 9,1 \\
\hline
\end{tabular}

Nihai halde Hat Efor Katsayısı formülü;

HEK $=(0,55-(($ Hattın İşletme Hızı-9,1) / $(39,4-9,1)) \times(0,55-0,30))$ / 0,45 şeklinde uygulanacaktır.

HEK, hesaplamasında herhangi bir hattın HEK katsayısı, sistemde normal kabul edilen değerlere göre olan sapmalarına göre hesaplanır. HEK için kullanılan değerler aşă̆ıda açıklanmıştır.
- 0,55 lt $12 \mathrm{~m}$ bir aracın $1 \mathrm{~km}$ de tüketeceği maksimum yakıt miktarını,

- 39,4 sistemdeki araçların maksimum ortalama hiz1,

- 9,1 sistemdeki araçların minumum ortalama hiz1,

- 0,30 lt $12 \mathrm{~m}$ bir aracın $1 \mathrm{~km}$ de tüketeceği minumum yakıt miktarını,

- 0,45 lt $12 \mathrm{~m}$ bir aracın $1 \mathrm{~km}$ de tüketeceği ortalama yakıt miktarını, ifade eder.

Herhangi bir hattın işletme hızı; hat efor katsayısının hesaplanma ayı içerisinde hatta çalışan araçların gerçekleştirdikleri toplam kilometrenin toplam çalışma sürelerine (saat) bölünmesiyle hesaplanır.

Sefer süresi verisi alınırken, hattın standart sapmasının dışında olan veriler hesaplamaya dahil edilmez.

Yakıt Birim Ödeme Tutarı: Hakedişe konu uygulama ayı içerisinde Enerji Piyasası Düzenleme Kurulu (EPDK) resmi internet sitesinde yayınlanan günlük motorin bayi satış fiyatları bülteni baz alınarak hesaplanır.

Maliyet tablosunda kullanılan akaryakıt birim fiyatı 01.01.2020 tarihli EPDK motorin fiyatına göre hesaplanmıştır. Hakediş ödemelerinde akaryakıt fiyatları aylık olarak EPDK fiyat verileri ve aşağıdaki tablo üzerinden güncellenir.

Tablo-3'de araç tiplerine göre ortalama yakıt tüketimleri verilmiştir. Araç tiplerine göre yakıt birim ödeme;

Yakıt Birim Ödeme =Motorin Fiyatı x Ortalama Yakıt Tüketimi

Tablo 3. Araç Uzunluğuna Göre Ortalama Yakıt Tüketimleri

\begin{tabular}{|l|c|c|c|c|c|}
\hline $\begin{array}{l}\text { Araç } \\
\text { Uzunluğu }\end{array}$ & $\mathbf{1 2 M}$ & $\begin{array}{c}\mathbf{1 2 M} \\
\text { Çift } \\
\text { Katlı }\end{array}$ & $\begin{array}{c}\mathbf{9 , 1 -} \\
\mathbf{1 1} \mathbf{M}\end{array}$ & $\mathbf{8 , 1 - 9 M}$ & $\begin{array}{c}\mathbf{6 , 5}- \\
\mathbf{8 M}\end{array}$ \\
\hline $\begin{array}{c}\text { Ortalama } \\
\text { Yakıt }(\mathrm{Lt} / \mathrm{Km})\end{array}$ & 0,45 & 0,52 & 0,35 & 0,32 & 0,28 \\
\hline
\end{tabular}

Bakım \& Onarım Birim Ödeme: Bakım \& Onarım Birim Ödemesi araç tiplerine göre farklılaşmakta olup EK-2 Maliyet tablosunda KM başına belirlenmiştir. Aylık 7.000-10.000 km arası için kilometre başına 0,10 €, 10.000 km’yi aşan kısmı için kilometre başına 0,25 モ ilave ödeme yapılır.

Performans Ödemesi: Performans ödemesi araç tiplerine göre farklılaşmakta olup EK-2 Maliyet tablosunda belirlenmiştir. Aylık 10.000 Km'yi aşan km için; maliyet tablosunda belirlenmiş olan performans ödemesinin 10.000 'e bölünmesi sonucu bulunacak miktarın 10.000 km'yi aşan kilometre miktarı ile çarpılması sonucu ortaya çıkacak olan bedel ilave performans ödemesi olarak hesaplanır.

Gerçekleşen Kilometre: İlgili güzergâhlarda gerçekleşmiş sefer sayısı ile bu güzergâhların kilometresinin çarpımı ile elde edilir.

Yukarıda verilenler 1şığında İstanbul toplu ulaşım sisteminde hizmet veren 3041 Özel Halk Otobüsü (ÖHO) ve İOAŞ işletmecisinin hakedişleri eski Net Maliyet Modeline ve yeni Brüt Maliyet Modeline göre hesaplamaları yapılmış, gelir ve karlılıklarda'ki değişimler Şekil-2 karşılaştırılmıştır. 


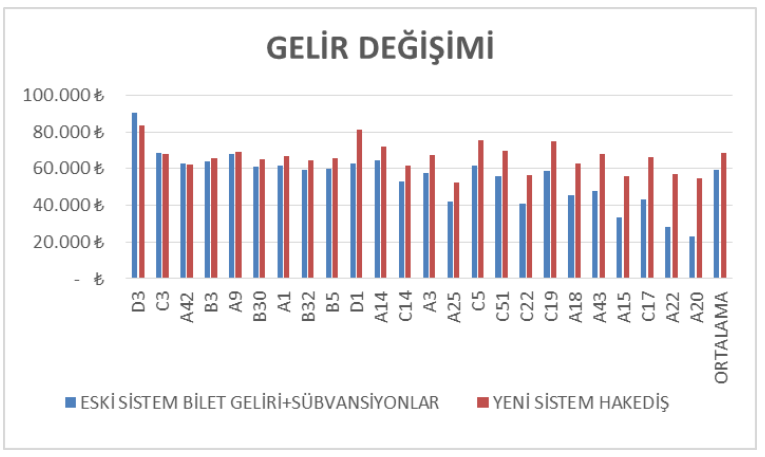

Şekil 2. Gelir Değişimi

Gelir değişimi incelendiğinde işletmecilerin \%91'nin geliri artmış, buna karşın \%9'unun geliri azalmış, havuzdaki paranın daha adil dağılımı sağlanmıştır. Ortalama'da ise \%10 yakın bir gelir artışı sağlanmıştır.

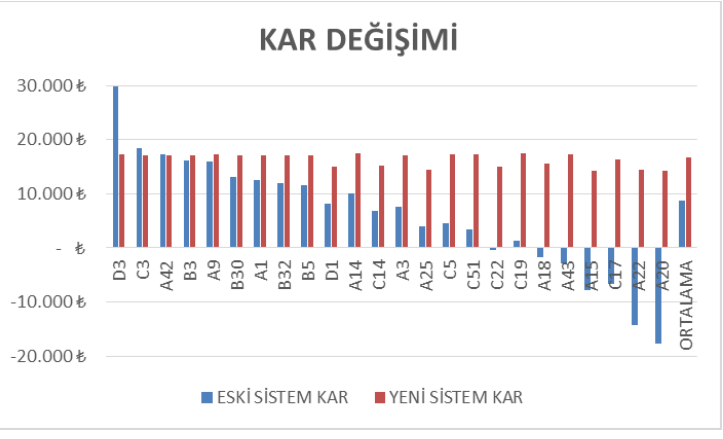

\section{Şekil 3. Kar Değişimi}

Karlılıklar incelendiğinde eski hakediş modelinde (Net Maliyet Modeli) aynı işletme hakları ile çalıșmalarına karşın bazı işletmecilerin 30.000 tl'ye varan karlılıkla çalışmakta iken bazı işletmecilerin -15.000 tl'ye yakın zararla çalıştıkları görülmektedir. Yeni hakediş sistemi (Brüt Maliyet Modeli) ile işletmeciler arasında ki kazanç adaletsizliği sonlandırılmış olup i aynı performansla çalışan işletmecilerin eşit kar elde ettiği, farklılıkların araç tiplerinden ortaya çıktığı görülmektedir.

İstanbul toplu ulaşım sistemi için önerilen performansa dayalı hakediş modelinin (Brüt Maliyet Modeli) avantajları, dezavantajları, firsatları ve tehditleri Tablo-4 de yer alan swot analizinde incelenmiş̧ir.

Tablo 4. Brüt Maliyet Sözleşmesi Swot Analizi

\begin{tabular}{|l|l|}
\hline \multicolumn{1}{|c|}{ Güçlü Yanlar } & \multicolumn{1}{c|}{ Zayıf Yanlar } \\
\hline $\begin{array}{l}\text { Operatör pazara girmek için } \\
\text { isteklidir }\end{array}$ & $\begin{array}{l}\text { Teşvik olmaması dolayısıyla } \\
\text { operatörler açısından ticari } \\
\text { kazancı düşük görülür }\end{array}$ \\
\hline $\begin{array}{l}\text { Otoriteye esnek planlama } \\
\text { imkânı tanır }\end{array}$ & $\begin{array}{l}\text { Yüksek seviyede denetim } \\
\text { gerektirir }\end{array}$ \\
\hline $\begin{array}{l}\text { İdare üzerinde siyasi bask1 } \\
\text { azalır, taraflar arası uyuşmazlık } \\
\text { olasılığı düşer }\end{array}$ & $\begin{array}{l}\text { Ulaşım Otoritesi detaylı } \\
\text { bilgiye ihtiyacı duyar }\end{array}$ \\
\hline Yolcu memnuniyeti artar & $\begin{array}{l}\text { Hizmet kalitesinde düşüşs } \\
\text { görülebilir }\end{array}$ \\
\hline $\begin{array}{l}\text { Operatör için finansal } \\
\text { sürdürülebilirlik sağlanır }\end{array}$ & $\begin{array}{l}\text { Maliyet riski operatörün } \\
\text { üzerindedir }\end{array}$ \\
\hline $\begin{array}{l}\text { Operatör performans odaklı } \\
\text { çalışır }\end{array}$ & \\
\hline
\end{tabular}

\section{4.Örnek Çalışma}

İstanbul'da yeni uygulanmaya başlayan hakediş sistemi neticesinde bazı araçların yeni hakediş sistemden önce aldığı ve sistemden sonra alacakları hakediş Tablo-5 de gösterilmiş̧ir.

$\mathrm{X} 1$ arac1 için;

$(30540 * 1+8355(0,925 * 2,78+0,4)) * 1,0375+15.270=72.714 \mathrm{TL}$

Aşağıdaki tabloda yakıt ve bakım birim bedeli sırasıyla 2,8 TL ve 0,4 TL olarak kabul edilmiştir.

Tablo 5. Örnek Hesaplama

\begin{tabular}{|c|c|c|c|c|c|}
\hline Araç & $\begin{array}{c}\text { Aylık } \\
\text { Km }\end{array}$ & HEK & SGO & $\begin{array}{c}\text { Yeni Sistem } \\
\text { Hakediş }\end{array}$ & Mevcut Hakediş \\
\hline $\boldsymbol{X} \mathbf{1}$ & 8355 & 0,925 & 1 & 72.714 & 73.873 \\
\hline $\boldsymbol{X} \mathbf{2}$ & 8355 & 0,925 & 1 & 72.714 & 68.544 \\
\hline $\boldsymbol{Y} \mathbf{1}$ & 6811 & 1,011 & 1 & 69.640 & 73.206 \\
\hline $\boldsymbol{Y} \mathbf{2}$ & 7022 & 1 & 1 & 70.130 & 65.823 \\
\hline
\end{tabular}

$\mathrm{X} 1$ ve X2 araçları aynı hatta çalışmış olup, yaptığ1 işin tamamen aynı olmasına rağmen yol içindeki yaşanan rekabet, sefer saatlerinin farklı olması vb nedenlerden dolayı farklı hakediş almışlardır. Fakat yeni sisteme geçilmesiyle beraber, alınacak hakediş sadece yapılan iş esasına göre ödeneceği için işletmecilerin gelir riski tamamen ortadan kalkmıştır.

\section{Değerlendirme ve Sonuç}

Şirketlerle yapılan görüşmeler ve ortak akıl toplantıları neticesinde İstanbul'da uygulanan hakediş sistemine 3041 özel taşımacının tamamıyla sisteme geçilmiştir.

Yukarıda bahsedildiği üzere dar bölgelerin (Hat araç eşleşmelerinin ve çalışma sıralamasının belirlendiği hat-araç küme) karlılıkları arasında büyük farklılıklar hem işletmeciler açısından, hem idare açısından hemde yolcular açısından memnuniyetsizlik sebeplerinin kök nedenini oluşturmaktaydı. Yeni modelle birlikte bu problem çözülmüş ve paydaş beklentilerini karşılamak için sisteme değişim ve yenileşim firsatı sunulmuştur. 
Hakediş modeline geçilmesi ile işletmeciler için gelir garantisi sağlanacak, yolda rekabetin önüne geçilip yol için rekabet ortamı oluşturarak hizmet kalitesi artacak ve hatlar arasındaki gelir-gider adaletsizliğini ortadan kaldıracaktır. Ayrıca iç müşteriler olan çalışanların memnuniyeti de artıracaktır.

Hakediş modeli, esnek hat planlamasına imkanı sağlaması, sefer kayıplarını azaltması, haksız rekabeti önlemesi, modlar arası entegrasyon ve hat optimizasyonu sorunlarına da çözüm üretmesi ile birlikte operatörlerin kurumsallaşması için önemli bir adım olacaktır.

Ulaşım hizmetlerinin bireylerin performansına veya hizmet anlayışına bağglı olmadan sürdürülmesi ve geliştirilmesi için kurumsallaşma büyük önem taşımaktadır. Kurumsallaşma için de hakediş modelinde ve hizmet standartlarında reform sağlanması gerekmektedir. Mevcut Net Maliyet Kontrat Modeli ile kurumsallaşma adımlarının gerçekleşmesi mümkün değildir.

Kurumsallaşma planlamaya esneklik kazandırmakta, sistemi politik etkenlere karşı korumakta ve ölçek ekonomisinden faydalanarak düşük maliyetler ile yüksek hizmet kalitesini sağlamayı hedeflemektedir. İşletmecilerin ölçek ekonomisinden yararlanabilmeleri için maliyet havuzu, filo havuzu ve personel havuzu gibi sistemler kurarak kurumsallaşma adına ilk adımlarını atmaları sağlanabilir. Dünyadaki gelişmiş toplu ulaşım sistemlerinde kurumsal operatörler veya global toplu ulaşım operatörleri ile bu hizmet sağlanmaktadır.

Bununla beraber önerilen sistemde kilometre başına gelir garantisi verildiğinden kaçak yolcu, usulsüz kart kullanımı gibi halen sıkı kontrol edilen konuların kontrol dışı kalabileceği düşünülmektedir. Eski sübvansiyonlarında etkisiyle yüksek kar marjına sahip hatlarda çalışan operatörlerin gelirlerinin düşebilecek olması veya çalışma şartlarının değişecek olması sisteme geçişi ilk etapta zorlasa da, toplu ulaşımda yaşanan siyasi ve dış faktörler (COVID-19 vb.) gibi belirsizlikler hat karlılıkları ne olursa olsun tüm taşımacıları daha istikrarlı olan yeni modele geçmeye itmiştir.

\section{Teşekkür}

Çalışmamıza verdiği destekten dolayı İETT İşletmeleri Genel Müdürlüğü'ne teşekkür ederiz.

\section{EK-1 Zayi Tasnif Tablosu}

Zayi tasnif tablosu Tablo-6'da gösterilmiştir.
Tablo 6. Sefer Zayi Tasnif Tablosu

\begin{tabular}{|c|c|c|}
\hline Zayi Türleri & \begin{tabular}{|c|} 
IETT \\
Kaynaklı \\
(En)
\end{tabular} & \begin{tabular}{|c|} 
İşleten \\
Kaynaklı \\
(Fn)
\end{tabular} \\
\hline$\overline{A R \prime \prime}>$ Arlza & & + \\
\hline DL" >Dilekçeli & & + \\
\hline $\begin{array}{l}F S^{\prime \prime}>\text { Fazla Sefer (gidilen yerde } \\
\text { zayi olmayacak) }\end{array}$ & + & \\
\hline GA" >Gözetim Altt-1 & & + \\
\hline GA" > Gözetim Altı-2 & + & \\
\hline$\overline{G G^{\prime \prime}>\text { Garajdan Geç Gelme }}$ & & + \\
\hline HD" > Hat Değiştirme & + & \\
\hline KZ" >Kaza-1 & & + \\
\hline KZ" $>$ Kaza-2 & + & \\
\hline OY" > Otobüs Yokluğu & & + \\
\hline PY" >Personel Yokluğu & & + \\
\hline YG" >Yolda Gecikme & + & \\
\hline YS" >Yolcu Sağlık vb Sorunlar & + & \\
\hline HM" >Hava Muhalefeti & + & \\
\hline TO" > Toplumsal Olaylar & + & \\
\hline TO" >Toplumsal Olaylar & & + \\
\hline CA" >Cihaz Arlzasl-1 & & + \\
\hline CA" >Cihaz Arlzasl-2 & + & \\
\hline $\begin{array}{l}\text { SD" >Personel Sağlık Durumu } \\
\text { (Yolda, belgeli) }\end{array}$ & + & \\
\hline KG" >Kapalı Güzergâh & + & \\
\hline $\begin{array}{l}\text { CI" >Servisten Men veya Ceza } \\
\text { Kaynakl Íptal }\end{array}$ & & + \\
\hline $\begin{array}{l}\text { KM" >Araç Muayene (IETT/ } \\
\text { Karayolları) }\end{array}$ & & + \\
\hline ST" > Saldirl \& Taciz-1 & & + \\
\hline ST" > Saldırı \& Taciz-2 (şoför) & + & \\
\hline RK" > Rötardan Kurtarma & + & \\
\hline $\begin{array}{l}\text { TK" > Temizlik \& Güvenlik \& } \\
\text { Kontrol İhtiyacl }\end{array}$ & + & \\
\hline $\begin{array}{l}\text { NM" > Normale Döndü-Zayi Karar } \\
\text { Iptali (Durum: Iptal silinmelidir) }\end{array}$ & + & \\
\hline AY" >Akaryakut Bitti & & + \\
\hline$\overline{A Z "}>$ Şoförün Yanlış Algılaması & & + \\
\hline IG" >ídari Görev & + & \\
\hline YH" > Yolcu Hasarl & + & \\
\hline
\end{tabular}

\section{EK-2 Sabit ve Değişken Ödeme Kalemleri}

Sabit ve Değişken Ödemeler Tablo-7'da gösterilmiştir. 
Tablo 7. Ödeme Tablosu

\begin{tabular}{|c|c|c|c|c|c|c|}
\hline \multicolumn{2}{|c|}{$\begin{array}{c}\text { GIDER } \\
\text { KALEMLERİ }\end{array}$} & \multirow{2}{*}{$\begin{array}{l}\mathbf{1 2} \\
\mathbf{M} \\
\text { dize } \\
\mathbf{l}\end{array}$} & \multirow{2}{*}{$\begin{array}{c}\text { ÇİFT } \\
\text { KATLI } \\
\\
1.084 \\
\text { TL }\end{array}$} & \multirow{2}{*}{\begin{tabular}{|c|}
$9,1-$ \\
$11 ~ M$ \\
\\
542 \\
TL
\end{tabular}} & \multirow{2}{*}{\begin{tabular}{|l|}
$8,1-9$ \\
M \\
\\
542 \\
TL
\end{tabular}} & \multirow{2}{*}{$\begin{array}{l}\mathbf{6 , 5 - 8} \\
\mathbf{M} \\
\\
542 \\
\text { TL }\end{array}$} \\
\hline \multirow{15}{*}{$\begin{array}{l}\text { SABITT } \\
\text { GIDER } \\
\text { KALEML } \\
\text { ERI }\end{array}$} & $\begin{array}{l}\text { Zorunlu } \\
\text { Trafik } \\
\text { Sigortast } \\
\end{array}$ & & & & & \\
\hline & Kasko & $\begin{array}{c}1.00 \\
0 \\
\mathrm{TL}\end{array}$ & $\begin{array}{l}1.246 \\
\text { TL }\end{array}$ & $\begin{array}{l}808 \\
\text { TL }\end{array}$ & $\begin{array}{l}600 \\
T L\end{array}$ & $\begin{array}{l}450 \\
\mathrm{TL}\end{array}$ \\
\hline & $\begin{array}{l}\text { Ferdi } \\
\text { Kaza } \\
\text { Sigortasl }\end{array}$ & $\begin{array}{l}60 \\
\text { TL }\end{array}$ & $60 \mathrm{TL}$ & $\begin{array}{l}60 \\
T L\end{array}$ & $\begin{array}{l}60 \\
\text { TL }\end{array}$ & $\begin{array}{l}60 \\
T L\end{array}$ \\
\hline & $\begin{array}{l}\text { MTV( } \\
\text { Motorlu } \\
\text { Taşıtlar } \\
\text { Vergisi) } \\
\text { orta. } \\
\end{array}$ & $\begin{array}{l}291 \\
\text { TL }\end{array}$ & $310 \mathrm{TL}$ & $\begin{array}{l}291 \\
\text { TL }\end{array}$ & $\begin{array}{l}291 \\
\text { TL }\end{array}$ & $\begin{array}{l}{ }^{2} \\
91 \\
T L\end{array}$ \\
\hline & $\begin{array}{l}T \ddot{U} V- \\
T \ddot{U} R K \\
\text { Muayene }\end{array}$ & $\begin{array}{c}5^{4} \\
\text { TL } \\
\end{array}$ & $\begin{array}{l}45 \\
\mathrm{TL}\end{array}$ & $\begin{array}{r}4 \\
5 \mathrm{TL}\end{array}$ & $\begin{array}{r}4 \\
5 \mathrm{TL}\end{array}$ & $\begin{array}{r}4 \\
5 \mathrm{TL}\end{array}$ \\
\hline & $\begin{array}{l}\text { Amortism } \\
\text { an }\end{array}$ & $\begin{array}{c}7.50 \\
0 \\
\text { TL } \\
\end{array}$ & $\begin{array}{c}9.346 \\
\text { TL }\end{array}$ & $\begin{array}{l}6.06 \\
0 \mathrm{TL}\end{array}$ & $\begin{array}{l}4.50 \\
0 \mathrm{TL}\end{array}$ & $\begin{array}{l}3.37 \\
5 \mathrm{TL}\end{array}$ \\
\hline & $\begin{array}{l}\text { Personel } \\
\text { (ideal 2,5 } \\
\text { sürücü) }\end{array}$ & $\begin{array}{c}10.0 \\
00 \\
\mathrm{TL} \\
\end{array}$ & $\begin{array}{l}10.000 \\
\text { TL }\end{array}$ & $\begin{array}{c}10.0 \\
00 \\
\text { TL } \\
\end{array}$ & $\begin{array}{c}10.0 \\
00 \\
\mathrm{TL} \\
\end{array}$ & $\begin{array}{c}10.0 \\
00 \\
\text { TL } \\
\end{array}$ \\
\hline & $\begin{array}{l}S G K, \\
\text { vergi ve } \\
\text { diğer } \\
\text { ödemeler } \\
\text { (ideal 2,5 } \\
\text { kişi) }\end{array}$ & $\begin{array}{c}6.25 \\
0 \\
\mathrm{TL}\end{array}$ & $\begin{array}{c}6.250 \\
\text { TL }\end{array}$ & $\begin{array}{l}6.25 \\
0 \mathrm{TL}\end{array}$ & $\begin{array}{l}6.25 \\
0 \mathrm{TL}\end{array}$ & $\begin{array}{l}6.25 \\
0 \mathrm{TL}\end{array}$ \\
\hline & $\begin{array}{l}\text { Kidem } \\
\text { Tazminatı } \\
(2,5 \\
\text { personel })\end{array}$ & $\begin{array}{c}1.14 \\
9 \\
T L\end{array}$ & $\begin{array}{l}1.149 \\
\text { TL }\end{array}$ & $\begin{array}{l}1.14 \\
9 \mathrm{TL}\end{array}$ & $\begin{array}{l}1.14 \\
9 \mathrm{TL}\end{array}$ & $\begin{array}{l}1.14 \\
9 \mathrm{TL}\end{array}$ \\
\hline & Muhasebe & $\begin{array}{l}500 \\
\text { TL } \\
\end{array}$ & $500 \mathrm{TL}$ & $\begin{array}{l}500 \\
\text { TL } \\
\end{array}$ & $\begin{array}{l}500 \\
\text { TL } \\
\end{array}$ & $\begin{array}{l}500 \\
\text { TL }\end{array}$ \\
\hline & $\begin{array}{l}\text { Shirket } \\
\text { Payl }\end{array}$ & $\begin{array}{l}490 \\
T L\end{array}$ & $490 \mathrm{TL}$ & $\begin{array}{l}490 \\
\mathrm{TL}\end{array}$ & $\begin{array}{c}490 \\
\mathrm{TL}\end{array}$ & $\begin{array}{l}490 \\
\mathrm{TL}\end{array}$ \\
\hline & $\begin{array}{l}\text { Personel } \\
\text { Elbisesi }\end{array}$ & $\begin{array}{l}150 \\
\text { TL }\end{array}$ & $150 \mathrm{TL}$ & $\begin{array}{l}150 \\
\text { TL }\end{array}$ & $\begin{array}{l}150 \\
\text { TL }\end{array}$ & $\begin{array}{l}150 \\
\text { TL }\end{array}$ \\
\hline & $\begin{array}{l}\text { Belediye } \\
\text { Ruhsat } \\
\text { Harcl } \\
\text { Ortalama }\end{array}$ & $\begin{array}{l}63 \\
\text { TL }\end{array}$ & $63 \mathrm{TL}$ & $\begin{array}{l}63 \\
\mathrm{TL}\end{array}$ & $\begin{array}{l}63 \\
\mathrm{TL}\end{array}$ & $\begin{array}{l}63 \\
\mathrm{TL}\end{array}$ \\
\hline & $\begin{array}{l}\text { Sabit } \\
\text { Bakım }\end{array}$ & $\begin{array}{c}2.10 \\
0 \\
\text { TL }\end{array}$ & $\begin{array}{c}2.368 \\
\text { TL }\end{array}$ & $\begin{array}{l}1.77 \\
6 \mathrm{TL}\end{array}$ & $\begin{array}{l}1.60 \\
0 \mathrm{TL}\end{array}$ & $\begin{array}{l}1.50 \\
0 \mathrm{TL}\end{array}$ \\
\hline & Ad Blue & $\begin{array}{c}400 \\
\text { TL }\end{array}$ & $400 \mathrm{TL}$ & $\begin{array}{l}400 \\
\text { TL }\end{array}$ & $\begin{array}{l}400 \\
\text { TL }\end{array}$ & $\begin{array}{l}400 \\
\text { TL }\end{array}$ \\
\hline \multicolumn{2}{|c|}{ SABITT TOPLAM } & $\begin{array}{c}30.5 \\
40 \\
\text { TL }\end{array}$ & $\begin{array}{c}\text { 33.460 } \\
\text { TL }\end{array}$ & $\begin{array}{c}28.5 \\
84 \\
\text { TL }\end{array}$ & $\begin{array}{c}26.6 \\
40 \\
\text { TL }\end{array}$ & $\begin{array}{c}25.2 \\
65 \\
\text { TL }\end{array}$ \\
\hline \multirow{2}{*}{$\begin{array}{l}D E \check{G} \dot{I S S} \\
E N \\
G \dot{I} D E R \\
K A L E M L \\
E R \dot{I}\end{array}$} & $\begin{array}{l}\text { Yakıt } \\
(T L / K m)\end{array}$ & $\begin{array}{c}2,78 \\
\text { TL }\end{array}$ & $3,24 \mathrm{TL}$ & $\begin{array}{c}2,16 \\
\text { TL }\end{array}$ & $\begin{array}{c}1,98 \\
\mathrm{TL}\end{array}$ & $\begin{array}{c}1,73 \\
\text { TL }\end{array}$ \\
\hline & $\begin{array}{l}\text { Baklm } \\
(T L / K m)\end{array}$ & $\begin{array}{c}0,40 \\
\text { TL }\end{array}$ & $0,45 \mathrm{TL}$ & $\begin{array}{c}0,35 \\
\text { TL }\end{array}$ & $\begin{array}{c}0,30 \\
\text { TL }\end{array}$ & $\begin{array}{c}0,29 \\
\text { TL }\end{array}$ \\
\hline \multicolumn{2}{|c|}{ DEĞISSKKEN TOPLAM } & $\begin{array}{c}3,18 \\
\text { TL }\end{array}$ & $3,69 \mathrm{TL}$ & $\begin{array}{c}2,51 \\
\text { TL }\end{array}$ & $\begin{array}{c}2,28 \\
\text { TL }\end{array}$ & $\begin{array}{c}2,02 \\
\text { TL }\end{array}$ \\
\hline \multicolumn{2}{|c|}{$\begin{array}{l}\text { MALIYET TOPLAMI } \\
(6600 \mathrm{Km} \text { yapan araç) }\end{array}$} & $\begin{array}{c}51.5 \\
20 \\
\text { TL }\end{array}$ & $\begin{array}{c}\mathbf{5 7 . 8 3 0} \\
\text { TL }\end{array}$ & $\begin{array}{c}45.1 \\
58 \\
\text { TL }\end{array}$ & $\begin{array}{c}41.6 \\
62 \\
\text { TL }\end{array}$ & $\begin{array}{c}38.5 \\
91 \\
\text { TL }\end{array}$ \\
\hline
\end{tabular}

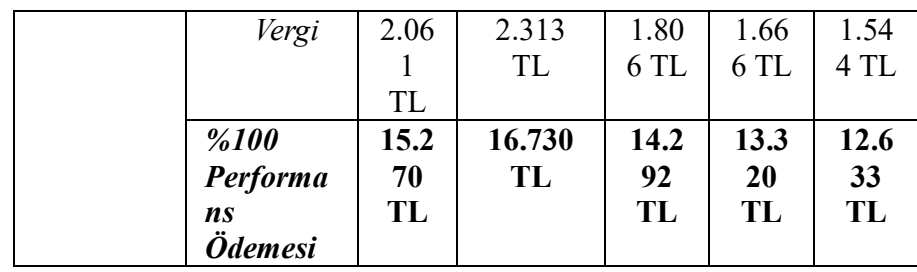

Maliyet tablosunun güncellenmesi 3 farklı TUİK endeksine göre yapılmıştır.

- Amortisman kaleminin güncellenmesinde; TUİK tarafindan aylık yayımlanan 2003=100 Temel Yıllı Üretici Fiyatları Sektörlere Göre Fiyat Endeksi ve Değişim Oranı Tablosunda 28 numaralı "Makine ve Teçhizat b.y.s." ürün sınıfi baz ayın içinde bulunduğu geçerli ay için verilen endeksi,

- Personel, SGK ve kıdem tazminatı kalemlerinin güncellenmesinde; TUİK tarafindan 3 aylık yayımlanan 2003=100 Temel Y1llı İşgücü Girdi Endeksleri ve Değişim Oranları tablosunda "Ticaret ve Hizmetler Alt Sektörü” baz dönemde içinde bulunduğu geçerli dönem için verilen endeksi,

- Yakıt hariç diğer kalemlerin güncellenmesinde ise; TUIK tarafindan aylık yayımlanan $2003=100$ Temel Yıllı Tüketici Fiyat Endeksi ve Değişim Oranları $(2003=100)$ Tablosunda baz ayın içinde bulunduğu geçerli ay için verilen endeksi kullanılmıştır.

- Akaryakıt birim fiyatı hesaplanırken 1 Ocak 2020 tarihli EPDK fiyatı baz alınmıştır. Akaryakıt birim ücreti ile ilgili fiyat değişiklikleri EPDK fiyat verileri üzerinden her ay güncellenir.

\section{Kaynakça}

Amaral, M., Saussier, S., \& Yvrande-Billon, A. (2013). Expected number of bidders and winning bids: Evidence from the london bus tendering model. Journal of Transport Economics and Policy (JTEP), 47(1), 17-34.

Camen, C. (2011). Organising Authorities Committee Public Transport Performance and Quality: Enhancing Bus Services Case Studies.

Cantillon, E., \& Pesendorfer, M. (2006). Auctioning bus routes: The London experience.

International Association of Public Transport (UITP). (2010). Organisation and Business Models.

International Association of Public Transport (UITP). (2016a). Contractual Arrangements Between Authorities and Operators.

International Association of Public Transport (UITP). (2016b). Public Transport Organisation \& Regulation Contractual Arrangements.

International Association of Public Transport (UITP). (2016c). Relationships Between Public Transport Actors and Business Models.

İstanbul Büyükşehir Belediyesi Meclis Kararları (İBB). 17.09.2020 tarih ve 906 sayılı karar. 
Leong, W., Goh, K., Hess, S., \& Murphy, P. (2016). Improving bus service reliability: The Singapore experience. Research in Transportation Economics, 59, 40-49.

Yıldızgöz, K. (2010). Toplu Taşımacılığın Organizasyonu İdareler ve İşletmeciler Arasındaki İlişkilerin Yönetimi.

Saussier, S., Tirole J. (2015) Strenghtening the Efficiency of Public Procurement (2-3)

Walters, J.,Jansson,J.Owen (2008) Risk and reward in public Transportation contract

Leong, W., Goh, K., Hess, S., Murphy, P.(2016) Improving Bus Service Reliability: The Singapore Exprience (42-43)

İmre, Ş. Çelebi D., (2017) Measuring Comfort İn Public Transport : A case study for İstanbul 